\title{
Feminismo e mulheres na resistência à ditadura brasileira de 1964-1985
}

\author{
Feminism and women in the resistance to the Brazilian \\ dictatorship of 1964-1985
}

\author{
Maria Elaene Rodrigues Alves*
}

\begin{abstract}
Resumo - Este artigo tem o objetivo de explicitar a participação política das mulheres na ditadura civil-militar no Brasil, tendo como referência a história do feminismo em seus vários períodos, leitura particular para se abordar a luta do movimento de mulheres no contexto ditatorial. As ações políticas das mulheres foram marcadas por recortes de classes, perspectivas teóricas distintas e formas diversas de engajamento. Este artigo é resultado de uma pesquisa cujo estudo se pautou em pesquisa bibliográfica, pesquisa documental no Centro de Referência das Lutas Políticas no Brasil de 1964-1985 - Arquivo Nacional do Estado do Rio de Janeiro, e entrevistas com mulheres que viveram as resistências e violências na ditadura brasileira de 1964-1985.
\end{abstract}

Palavras-chave: ditadura civil-militar; política; feminismo; movimento de mulheres; relações patriarcais.

\begin{abstract}
This article aims to explain the political participation of women during the civic-military dictatorship in Brazil, having as reference the history of feminism in its various periods, particular reading to address the struggle of the women's movement in the dictatorial context. Women's political actions were marked by class, different theoretical perspectives, and diverse forms of engagement. This article is the result of a research whose study was based on bibliographic research, documentary research at the Reference Center of Political Struggles in Brazil from 1964-1985-Brazilian National Archives, and interviews with women who lived the resistance and experienced violence during the Brazilian dictatorship of 1964-1985. Keywords: civic-military dictatorship; politics; feminism; women's movement; patriarchy.
\end{abstract}

\footnotetext{
* Doutora em Serviço Social pela Universidade do Estado do Rio de Janeiro (UERJ). Professora do Curso de Serviço Social da Universidade de Brasília (UnB). E-mail: elaene@unb.br. ORCID: https://orcid.org/0000-0001-8233-9558.
} 


\section{Introdução}

Na história da ditadura civil-militar no Brasil (1964-1985), as mulheres estiveram presentes em movimentos de contestação às perdas de direitos e às inúmeras violências do Estado, organizando-se em partidos e movimentos sociais, atuando junto às massas. Por sua vez, também se registram ações das que saíram às ruas para pedir a deposição do presidente João Goulart (setembro de 1961 a março de 1964). Neste caso, eram muIheres de classe média, de perfil conservador e temorosas com o que era construído pela grande imprensa e por outras instituições do "perigo comunista", que, juntamente com setores do clero e das elites rurais e urbanas, tiveram papel estratégico na instalação do período ditatorial.

Existia uma estratégia discursiva de generalizar o rótulo comunista para aumentar a gravidade ou a sensação de perigo em relação a certas mudanças sociais que incomodam a opinião conservadora. A discussão desse período se intercala com a história do movimento feminista e sua expressão na sociedade brasileira, um movimento que produz sua reflexão crítica e sua própria teoria. Nessa análise, reconhece-se a existência de várias concepções de feminismos e vertentes teóricas que direcionam as ações das feministas, como as liberais, a teoria queer (queer theory), as estruturalistas, as pós-coloniais, as pós-modernas, o feminismo e marxismo, o feminismo negro, o feminismo comunitário, o eco-feminismo etc. Por sua vez, deve-se pressupor que nem todas as organizações do movimento de mulheres se definem como parte do movimento feminista.

Este artigo é subsidiado pelo marxismo feminista, cuja especificidade está na preocupação de um debate teórico que resgate e elabore categorias voltadas "[...] para a compreensão crítica da subordinação histórica e das desigualdades que marcam a vida das mulheres, como de se instrumentalizar para intervir politicamente na reversão dessa condição" (CISNE, 2012, p. 59). O texto está dividido em duas seções principais. A primeira trata de analisar uma parte da história do feminismo e, na segunda seção, abordaremos a participação política das mulheres no enfrentamento à ditadura brasileira de 1964-1985.

\section{Feminismo e as lutas das mulheres na ditadura brasileira}

Compreende-se movimento feminista como de caráter social, uma práxis que é tanto teórica quanto política voltada à superação de realidade, sendo marcada por dominação/exploração de caráter patriarcal-racistacapitalista. Sua pauta propõe a igualdade e a liberdade para mulheres que só pode estar voltada à emancipação humana. Isto implica superar a dicotomia de mundo público como privilégio e domínio masculinos, enquanto se delega às mulheres a esfera privada. 
As mulheres, para a sociedade patriarcal, têm sido importantes no processo da reprodução social, cujo formato subjetivo e organizador do cotidiano as transformam nas principais responsáveis pelo trabalho doméstico. Já os homens, por sua vez, são considerados a "mola mestra do processo produtivo" e, portanto, "provedores" econômicos da família (ALVES; VIANA, 2008, p. 18). A divisão sexual do trabalho se constituiu historicamente como longo e crescente processo de apropriação de instrumentos de trabalho pelos homens, em seguida, da propriedade e das riquezas. É processo anterior à sociedade capitalista, embora nesta relação social desenvolva sua forma amadurecida e, consequentemente, consolide a dominação patriarcal.

A despeito da dinâmica histórica, a divisão sexual do trabalho se reproduziu ideologicamente como se fora um estado "natural" e imutável, o que não é. A separação espaço/tempo entre trabalho produtivo e trabalho reprodutivo instala-se com a chegada da ordem social capitalista. Do ponto de vista histórico, é possível observar que a "estruturação atual da divisão sexual do trabalho surgiu simultaneamente ao capitalismo" e que a relação do trabalho assalariado não teria podido se estabelecer na ausência do trabalho doméstico. Mesmo partindo do pressuposto de que houve, anteriores ao capitalismo, outras formas de divisão do trabalho entre homens e muIheres, essa divisão estava marcada por outra relação entre produção e reprodução, pois a divisão que se expressa nesse sistema está diretamente relacionada à formação social capitalista, na qual a força de trabalho é vendida como uma mercadoria e o espaço doméstico passa a ser uma unidade familiar e não mais uma unidade familiar e produtiva (ÁVILA, 2015, p. 19).

Essa divisão entre homens e mulheres na formação capitalista cria várias formas de exploração e subordinação do trabalho doméstico, em geral não o reconhecendo como trabalho, ademais de estar intimamente interligado ao domínio patriarcal. Na tentativa de contribuir com esse debate, as feministas materialistas afirmam que uma das bases de sustentação do modo capitalista de produção está na exploração do trabalho da mulher. Tal processo se dá na esfera produtiva - ocupando cargos desvalorizados e recebendo baixos salários - como também na esfera reprodutiva - materializada na família, através do trabalho doméstico, das tarefas reprodutivas e de cuidado não remuneradas (CISNE, 2012). Essa divisão se apresenta como determinante para a compreensão de como se organizam as hierarquias sociais com predominância dos homens em relação às mulheres, o que se observa nas formas de exploração, opressão e autoridade.

Nestes termos são produzidas relações de subordinação das muIheres a partir de uma moral sexual, a tolerância à violência que as atinge diretamente, dada a sua condição feminina, os limites legais e ideológicos que permitem o controle da sua capacidade reprodutiva. Pateman (1993) estabelece três grandes momentos do debate sobre o patriarcado: o primeiro, 


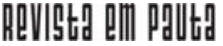

\} FEMINISMO E MULHERES - ALVES, M. E. R. \}

DOI: $10.12957 /$ rep.2021.56080

forma clássica no século XVII, incorpora todas as relações de poder ao regime patriarcal, inclusive justificando o absolutismo a partir do argumento de que "os reis eram pais e os pais eram reis". Com o desenvolvimento de elaborações teóricas modernas, de 1861 até o século XX, expande-se essa ideia de domínio paterno para a teoria do direito e da obediência, fazendose no modo "fraternal, contratual e estrutural à sociedade civil capitalista" (PATEMAN, 1993, p. 44-45).

O terceiro momento do debate ocorre com o nascimento do movimento feminista organizado, ainda em curso atualmente. Compreendese que o patriarcado está presente em várias sociedades, mas na capitalista/ racista torna-se mais complexo porque diferentes concepções ideológicas, culturais e políticas se entrelaçam. Passam a ser observadas não mais apenas nos limites do espaço doméstico, mas também no trabalho, na política e em outros espaços públicos. Com isso, as mulheres sofrem as relações de opressão e de violência que se estendem para além da casa para diferentes espaços públicos, sejam os do ambiente urbano ou rural.

Em situações de violência do Estado, a exemplo das ditaduras na América Latina nas décadas de 1960 a 1980, as mulheres registraram a brutalidade das torturas de seus corpos na forma de estupros e outras violências de caráter sexual. Por sua vez, estudantes presas por suas participações no Congresso da União Nacional dos Estudantes (UNE) em Ibiúna (SP), em 1968, indicaram que as forças policiais mostravam caixas de pílulas apreendidas, sugerindo outros motivos para estarem no evento, tal como no estudo de Ventura (1988, p. 35).

A polícia acreditava que a exibição provaria à opinião pública que as moças tinham ido ao encontro preparadas para algo mais do que discutir as questões estudantis. Portanto, os discursos de militares e outros agentes do governo aliavam aspectos morais à política para dissipar argumentos dos que faziam oposição à ditadura.

Em casos como estes, a violência efetuada pelo Estado contra as mulheres se legitimaria não apenas através de uma suposta política de segurança nacional, mas também por meio da violência patriarcal.

No que se refere à especificidade do patriarcado, Saffioti (1992) analisa a abordagem weberiana da categoria, fazendo crítica ao autor por apresentar o patriarcado unicamente como dominação centrada na família. A dominação-exploração do sistema patriarcal se inscreve tanto no espaço familiar quanto na esfera política, sendo intrínseco às relações sociais. Assim, "nem sequer a presença do patriarca é imprescindível para mover a máquina do patriarcado. A legitimidade atribui sua naturalização" (SAFFIOTI, 2004, p. 101), o que pode ser acionado, inclusive, por mulheres. Em síntese, para a autora, o sistema patriarcal tem quatro características essenciais: 1. Não se trata de uma relação apenas privada, mas civil; 2. Tem uma base material; 
3. Corporifica-se; e 4. Representa uma estrutura de poder baseada tanto na ideologia, quanto na violência.

Camurça (2007) reitera o pensamento de Saffioti (2004) ao apontar mecanismos que dão sustentabilidade ao sistema de dominação patriarcal. Este, sistematicamente, se reinventa e se reproduz através da "prática de violência para subjugá-las; pelo controle sobre o corpo, sua sexualidade e a vida reprodutiva das mulheres; a manutenção de dependência econômica e interdição à participação política das mulheres" (CAMURÇA, 2007, p. 20).

A violência contra a mulher, uma das práticas mais antigas e usuais da dominação patriarcal, caracteriza-se como ameaça constante às suas vidas quando ousam contrariar dado padrão de comportamento feminino, violência recorrente nos espaços públicos e privados. Se essa violência se expressa como relação de opressão, exploração e dominação que atinge todas as mulheres, no caso do Brasil volta-se, principalmente, para as pobres e negras. Isto é revelado pelos dados do feminicídio no país, levantados pelo Instituto de Pesquisas Econômicas Aplicadas (IPEA, [2020]): entre as mulheres assassinadas entre 2001 e 2011, 61\% eram negras e se concentraram principalmente nas regiões Nordeste $(87 \%)$, Norte $(83 \%)$ e CentroOeste $(68 \%)$.

O segundo mecanismo apresentado por Camurça (2007) diz respeito à dominação sobre o corpo das mulheres. Isto é evidente nos contextos de ditadura e de regimes autoritários na forma como as mulheres são tratadas na prisão, momentos em que a violência psicológica e sexual expressam marcas de poder e dominação política. Outro mecanismo apontado pela autora se fundamenta na manutenção da dependência econômica das muIheres que disputam de modo desigual o espaço no mercado de trabalho.

Por último, Camurça (2007) lembra a restrição de participação das mulheres na esfera político-institucional (partidos políticos, sindicatos e movimentos sociais diversos), sempre em menor número e, em geral, distantes dos postos de comando e direção, o que foi evidenciado na ditadura civil-militar.

\section{A participação política das mulheres na ditadura brasileira de 1964-1985}

Compreende-se o feminismo como ação política das mulheres visando à transformação de sua própria condição social, ação voltada a "transformar a si mesmas e ao mundo" (SOARES, 2004). O marco do seu surgimento foi a Revolução Francesa (1789), ao revelar a importância das mulheres que participaram massivamente daquela e de outras lutas. Ao se insurgirem, as mulheres questionaram a ordem vigente, a Igreja e a monarquia e reivindicaram direitos políticos. Abria-se uma era em que as mu- 


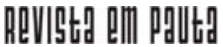

\} FEMINISMO E MULHERES - ALVES, M. E. R. \}

DOI: $10.12957 /$ rep.2021.56080

Iheres começaram a lutar pelo direito de participar ativamente da vida pública, considerando aspectos do trabalho, da educação e da representatividade política, o que foi melhor expresso na Comuna de Paris, quando assumiram "compromisso de classe com a luta socialista" (GURGEL, 2011, p. 33). Em linhas gerais, ao expressarem reivindicações por direitos civis e políticos, buscavam apoio para seus próprios interesses, que implicavam igualdade e liberdade para todos e todas.

Daquele momento em diante, em diferentes conjunturas, o feminismo ocupa a cena pública, com suas bandeiras e estratégias em direção ao questionamento e superação das bases da exploração-dominação que demarcam a experiência das mulheres ao longo da história patriarcal. O "feminismo trouxe à tona questões que não apenas estavam ligadas ao interesse das mulheres, mas também confrontavam diretamente os mecanismos de exploração do capital (GURGEL, 2011, p. 126).

A partir da segunda metade do século XIX, surge o "movimento sufragista", que se convencionou denominar como "primeira onda" do feminismo, "quando as mulheres, primeiro na Inglaterra, organizaram-se para lutar por seus direitos, sendo que o primeiro deles que se popularizou foi o direito ao voto" (PINTO, 2003, p. 16). Essa luta sufragista, presente em vários países do mundo, não foi processo fácil e segue como necessário para se alcançar a paridade nas instituições políticas, atualizando a importância da decisão política coletiva.

No caso brasileiro, embora o direito ao voto tenha sido conquistado em 1932, a participação da mulher na política continua limitada, na medida em que o modelo patriarcal encara as mulheres como cuidadoras da família e ainda não as considera como sujeitos políticos plenos. Não é natural, por exemplo, que apenas $9 \%$ dos parlamentares sejam mulheres (FARIA; NOBRE, 2014).

Portanto, a história do feminismo seguiu com avanços e desafios entrelaçada à história da construção de projeto coletivo que confrontasse a própria desigualdade capitalista, como fizeram mulheres anarquistas e comunistas, deflagrando "a luta contra a jornada intensa e extensa de trabalho, a desigualdade salarial e a exploração capitalista de uma maneira geral" (CISNE, 2012, p. 134).

Uma segunda onda do feminismo situa-se entre os anos 1960 e 1980 e corresponde ao processo mundial bastante intempestivo, momento em que os Estados Unidos entravam com todo o seu poderio na Guerra do Vietnã. Esse segundo movimento recebeu o slogan "O pessoal é político", com lutas voltadas a combater estruturas sexistas de poder (PINTO, 2003).

No contexto nacional, a primeira autora a sistematizar os estudos feministas de gênero foi Saffioti, com a obra $A$ mulher na sociedade de classes, de 1969, em que tratou das condições de vida e de trabalho das operárias têxteis da cidade de São Paulo (SP). Na Europa, por sua vez, 


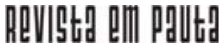

\} FEMINISMO E MULHERES - ALVES, M. E. R. \}

DOI: $10.12957 /$ rep.2021.56080

aconteceu o "Maio de 68", quando, em Paris, estudantes ocuparam a Sorbonne, pondo em xeque a ordem acadêmica estabelecida há séculos.

Durante [aquela] década, na Europa e nos Estados Unidos, o movimento feminista surge com toda a força e as mulheres, pela primeira vez, falam diretamente sobre a questão das relações de poder entre homens e mulheres. $\mathrm{O}$ feminismo aparece como um movimento libertário, que não quer só espaço para a mulher - no trabalho, na vida pública, na educação -, mas que luta, sim, por uma nova forma de relacionamento entre homens e mulheres, em que esta última tenha liberdade e autonomia para decidir sobre sua vida e seu corpo. Aponta, e isto é o que há de mais original no movimento, que existe uma outra forma de dominação - além da clássica dominação de classe -, a dominação do homem sobre a mulher - e que uma não pode ser representada pela outra, já que cada uma tem suas características próprias. [...] no Brasil, a década de 1960 teve uma dinâmica diversa em relação ao resto do mundo. O país, nos primeiros anos da década, teve grande efervescência. Já no ano de 1963 foi de radicalizações: de um lado, a esquerda partidária, os estudantes e o próprio governo; de outro, os militares, o governo norte-americano e uma classe média assustada. Em 1964, veio o golpe militar, relativamente moderado no seu início, mas que se tornaria, no mitológico ano de 1968, uma ditadura militar das mais rigorosas, por meio do Ato Institucional no 5 (AI-5), que transformava o Presidente da República em um ditador. (PINTO, 2003, p. 16).

A participação política das mulheres brasileiras nos anos de 1960 e 1970 foi diferenciada, como já referida. Em parte, deu sustentação à ditadura civil-militar, enquanto outras resistiram ao regime opressivo articulado pelo grande capital para ampliar seus níveis de exploração do trabalho. Esta resistência não ocorreu por um viés explicitamente feminista. As mulheres assumiram a condição de militantes das organizações de esquerda mais pela convicção política do que pelo fato de serem mulheres.

[...] poucas [...] ocupavam postos de direção nas organizações de esquerda. Outro fator importante é que a condição da mulher não tinha relevância na vida das organizações de esquerda, pois não era tratada política ou teoricamente. Somente após a reorganização da esquerda brasileira, no final dos anos 1970, a questão da mulher passa a ser debatida. (COLLING, 1997, p. 67).

Por sua vez, naquele momento, surgiu um movimento de muIheres de massa e com enraizamento popular que foi caracterizando por Sarti (1998) como uma "trajetória particular do feminismo". Assim, o movimento de mulheres no Brasil, nesse período, formou-se a partir de duas vertentes principais que se cruzaram: militantes feministas vinculadas ou originárias das organizações e partidos de esquerda e mulheres organizadas nos movimentos populares, em comunidades eclesiais de base, nos clubes 


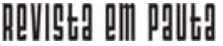

\} FEMINISMO E MULHERES - ALVES, M. E. R. \}

DOI: $10.12957 /$ rep.2021.56080

de mães, em movimentos reivindicativos, de saúde, de creches etc. Tais vertentes, por sua vez, comportavam uma multiplicidade de inserções, de níveis de organização, de priorização de áreas de luta e reivindicações e, obviamente, de visões do que é, ou deveria ser, o movimento de mulheres.

Com o tempo, parte das mulheres vinculadas às organizações e partidos de esquerda passou a atuar politicamente articulada ao conjunto das lutas e mobilizações dos direitos das mulheres, dando à sua atuação um tom próprio. Influenciaram e foram influenciadas pelas demandas das camadas populares, reportando-se também às mudanças em várias lutas no sentido de propor garantia dos direitos particulares das mulheres. Em meio à ditadura civil-militar, esse movimento chegou a ser considerado como um desvio pequeno-burguês por parte de segmentos da esquerda, como adverte Ventura (1988, p. 36): "Eram tempos difíceis aqueles da ditadura militar. Especialmente para as mulheres que tinham que lutar contra o inimigo externo - os militares, e com o interno - as organizações de esquerda, que olhavam para aquele movimento com a impaciência".

De fato, as bandeiras consideradas "específicas das mulheres" as que se referem ao combate à violência contra a mulher, demandas por creches e mesmo a própria participação feminina nas organizações - representavam risco para a luta central, na concepção de dirigentes de partidos e organizações, que era exclusivamente contra a ditadura civil-militar. Pateman (1993) adverte que a posição de igualdade entre homens e muIheres tem que ser aceita como expressão de liberdade das mulheres, o que não significa igualá-las aos homens. Entretanto, as militantes de esquerda se engajaram na luta de resistência à ditadura negando sua própria condição de mulher, enquanto as próprias organizações, espaços eminentemente masculinos, "impunham" às mulheres a necessidade de se colocarem como militantes, diluindo as relações de gênero na luta política mais geral.

Muitas barreiras começaram a ser rompidas na metade dos anos de 1970 e iriam marcar uma reviravolta do movimento feminista, colocando no centro das discussões a relação homem-mulher. A produção teórica sobre a condição feminista aparece com força neste período. Em 1971, em plena vigência do Al-5, a feminista Betty Friedan foi convidada para o lançamento de seu livro da mística feminina. Betty e um grupo de feministas americanas haviam escandalizado o mundo inteiro com a queima do sutiã em praça pública, simbolizando a liberdade da mulher (COLLING, 1997).

Assim, desenrolam-se debates feministas e lutas pela anistia e liberdades democráticas - todas como símbolos da oposição à ditadura civilmilitar. Além disso, incluíam matérias específicas, tais como violência doméstica, condições de trabalho das mulheres, direitos reprodutivos, aborto e sexualidade, demandas pelas creches e outros direitos sociais. Antes tímidos, esses debates passaram a ser mais explícitos, especialmente em veículos de caráter militante: os jornais Brasil Mulher e Nós Mulheres. Essa 
imprensa feminista alternativa, surgida em São Paulo na metade dos anos 1970, "[...] se tornou um espaço de expressão de uma linha política intimamente vinculada ao despertar das mulheres para as ideias feministas do período posterior à luta armada contra a ditadura no Brasil" (LEITE, 2003, p. 78.).

O movimento feminista brasileiro, incipiente e em consonância com o feminismo latino-americano, se consolidou e se ampliou em meados da década de 1970, no contexto da luta contra a ditadura civil-militar (1964-1985). Foi o momento em que apareceram os sinais de aguda crise econômica - elevação das taxas de desemprego e subemprego, arrocho salarial e corte de gastos sociais - e que emergiram lutas pertinentes ao cotidiano de mulheres populares como o Movimento contra a Carestia. Ao mesmo tempo, foi um contexto de ebulição política, social e cultural, de efervescência em torno das liberdades civis e de igualdade de direitos. Nestas lutas as mulheres foram assumindo papel importante, atuando no campo da política em geral e, especificamente, no que se refere às relações patriarcais, como o caso da luta pelo direito ao divórcio. Isso rompia radicalmente com códigos e imposições da época.

Se o movimento feminista surgiu e se fortaleceu no Brasil durante os anos de 1970 e 1980, tornou-se mais forte no processo de redemocratização do país. No território brasileiro, conforme já exposto, a história da participação das mulheres na cena política e social, naquele período, nem sempre esteve marcada pelo viés explicitamente feminista, embora se constituísse em uma novidade. Era o tempo em que o movimento operário se organizava para intervir como "ator mais importante neste cenário" (SOUZA-LOBO, 1991, p. 269).

No final dos anos 1970, diversos setores sociais liderados pelas mulheres se uniram em torno da campanha contra a intensificação das torturas e das medidas ditatoriais. Muitas mulheres tiveram um papel fundamental na luta pelo movimento da anistia política e, nos anos 1980, uniram esforços em torno da campanha pelas "Diretas-Já".

Enfim, as mulheres tiveram um papel de extrema importância no combate ao regime militar implantado no Brasil, saíram às ruas, muitas vezes, em passeatas exclusivamente femininas, esconderam armas, foram à luta armada, abrigaram militantes, traduziram jornais comunistas estrangeiros e organizaram sequestros. Além disso, romperam com estereótipos do ser mulher em relação à vida pública e privada (CARVALHO, 1992).

Enquanto as mulheres no Brasil organizavam as primeiras manifestações, as exiladas, principalmente em Paris, na França, entravam em contato com o feminismo europeu e começavam a se reunir e conhecer os debates naquele cenário. Tal processo se deu apesar da grande oposição dos homens exilados, seus companheiros na maioria, que viam o feminismo como um "desvio" na luta pelo fim da ditadura e pelo socialismo. Um exemplo dessa organização é o Círculo de Mulheres Brasileiras, que foi 


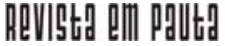

\} FEMINISMO E MULHERES - ALVES, M. E. R. \}

DOI: $10.12957 /$ rep.2021.56080

constituído por 20 militantes, sob influência do feminismo francês, em abril de 1976, na cidade de Paris. O círculo chegou a contar com 100 muIheres (GOLDENBERG, 1997).

Uma carta política lançada pelo Círculo da Mulher dá uma boa medida da difícil situação em que estas mulheres se encontravam.

Ninguém melhor que o oprimido está habilitado a lutar contra a sua opressão. Somente nós, mulheres organizadas autonomamente, podemos estar na vanguarda dessa luta, levantando nossas reivindicações e problemas específicos. Nosso objetivo ao defender a organização independente das mulheres não é separar, dividir, diferenciar nossas lutas das lutas que conjuntamente homens e mulheres travam pela destruição de todas as relações de dominação da sociedade capitalista. (PINTO, 2003, p. 54).

Trata-se, de fato, de análise sobre o pensamento político de muIheres que romperam laços autoritários de dominação e que, de várias formas, contribuíram para mudar a história do Brasil. Esta é a história particular das mulheres, cuja importância exige que seja contada e registrada pelo pensamento crítico, mesmo que em oposição a determinado tempo histórico da esquerda masculina brasileira.

O slogan do Movimento Feminista dos anos 1970, Nosso corpo nos pertence, alerta para a problemática da autonomia das mulheres em relação a decidir sobre seu próprio corpo, afirmando que através do corpo é que se expressa a vivência da sexualidade, não podendo, desta forma, ser considerado como um simples invólucro de reprodução dos seres humanos por meio da maternidade. O movimento feminista, naquele momento de repressão, traduzia a rebeldia das mulheres ao identificarem sua situação subordinada e ausência de igualdade. Elas procuraram construir proposta ideológica que revertesse a desigualdade e opressão. Isto só poderia se concretizar construindo um fazer político que negasse os mecanismos impeditivos do desenvolvimento de uma consciência como seres autônomos, superando a negação de as mulheres participarem da vida pública e privada.

As feministas fazem do conhecimento e da eliminação das hierarquias sexuais seu objetivo central e, a partir dessa realidade, se articulam com as outras vertentes do movimento de mulheres, pois a luta era por liberdade, democracia e justiça social. Pode-se afirmar, portanto, que a presença das mulheres na cena social brasileira nas últimas décadas tem sido inquestionável. A presença das mulheres na arena política foi, assim, construída no período da ditadura, a partir dos anos 1960, sendo um dos elementos que contribuíram para os processos de mudanças no regime político; além disso, mulheres também compuseram a coluna vertebral de muitas das organizações de sociedade civil e partidos políticos de oposição que, 
com êxito, desafiaram regras autoritárias durante os anos 1970 e início dos 1980 (ALVAREZ, 1998).

Com a redemocratização dos anos 1980, o feminismo no Brasil avança com a organização de inúmeros grupos e coletivos em todas as regiões, com objetivo de tratar sobre amplos temas: debate e lutas sobre aborto, violência, sexualidade, direito ao trabalho, igualdade no casamento, direito à terra, direito à saúde materno-infantil, luta contra o racismo, orientação sexual, entre outros. Os grupos se organizavam, algumas vezes, muito próximos dos movimentos populares de mulheres que estavam nos bairros pobres e favelas. Estes movimentos particulares lutavam por educação, saneamento, habitação e saúde e eram fortemente influenciados pelas comunidades eclesiais de base da Igreja Católica.

Outras mulheres, por sua vez, ampliaram a militância no espaço partidário e foram se construindo e se desenvolvendo no campo do pensamento de esquerda. Neste campo, o feminismo enfrentava o tensionamento com a própria esquerda e, para manter a convivência, exigia-se uma visão crítica da própria relação. De fato, é possível afirmar que a resistência política na luta específica das mulheres desafiou e continua a desafiar as organizações de feministas no interior dos partidos de esquerda. Isto é, a construção de um programa estratégico que considere não apenas a classe, mas também as relações patriarcais, divisão sexual do trabalho entre homens e mulheres, raça/etnia, participação da mulher na política, é importante porque, em realidade, é constitutiva das lutas mais amplas pela igualdade e liberdade.

[...] O feminismo brasileiro nasceu e se desenvolveu em um dificílimo paradoxo: ao mesmo tempo que teve de administrar as tensões entre uma perspectiva autonomista e sua profunda ligação com a luta contra a ditadura militar no Brasil, foi visto pelos integrantes desta mesma luta como um sério desvio pequeno-burguês. (PINTO, 2003, p. 45).

Abordar essa questão requer entender a categoria patriarcado, reconhecendo-a como histórica e em relação à qual se pode estabelecer, também, uma periodização. Além disto, este conceito é importante para compreender as relações de opressão dos homens em relação às mulheres em várias sociedades e em períodos diferentes. Segundo Saffioti (2004, p. 136), o patriarcado é um sistema de dominação anterior ao capitalismo e "[...] refere-se a milênios da história mais próxima, período no qual se implantou uma hierarquia entre homens e mulheres, com primazia masculina".

No sistema capitalista, esta hierarquia é mantida e estruturada a partir da coexistência entre capitalismo-patriarcado-racismo e por meio da relação exploração/dominação das mulheres. Esses elementos se modificam em diferentes processos do desenvolvimento deste sistema, mas permanecem como fundantes à sua reprodução e, em relação às desigual- 


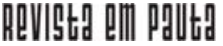

\} FEMINISMO E MULHERES - ALVES, M. E. R. \}

DOI: $10.12957 /$ rep.2021.56080

dades entre homens e mulheres, contribuem cotidianamente para a opressão das mulheres nessa sociedade.

Para compreender os efeitos conjugados dessas categorias sociais, Kergoat (2010) propõe a utilização dos conceitos de consubstancialidade e coextensividade para envolver, de maneira não mecânica, as práticas sociais de homens e mulheres. As relações sociais de classe, patriarcais e de raça são consubstanciais; elas formam um nó que não pode ser desatado no nível das práticas sociais, mas apenas na perspectiva da análise sociológica. Essas também são coextensivas, pois, ao se desenvolverem, as relações sociais se reproduzem e se coproduzem mutuamente. Nos termos de Safiotti (1987, p. 60), "[...] na realidade concreta, essas variáveis são inseparáveis, pois se transformaram, através desse processo simbiótico, em um único sistema de dominação-exploração, aqui denominado: patriarcado-racismocapitalismo".

De fato, o processo de exploração-dominação legitima a hierarquização masculina na sociedade ao estabelecer a liberdade para os homens e a submissão às mulheres. Ao entender esse sistema de poder masculino, observam-se múltiplas faces da dominação-opressão e exploração sobre as mulheres: econômica, política e sexual. Isto se evidenciou, principalmente, no período de ditadura civil-militar com as várias violações enfrentadas por essas mulheres. Nessa direção, é possível utilizar a categoria patriarcado como foi empregada pelo feminismo dos anos de 1970. Isto é, "[...] indica uma formação social onde os homens detêm o poder, ou ainda, simplesmente: o poder dos homens" (DELPHY, 2000, p. 141).

É importante lembrar a expressão crítica de Elizabeth Souza-Lobo (1991), "a classe operária tem dois sexos", que dá título ao seu livro (1991). Aqui se desenvolve uma crítica aos clássicos da teoria crítica e ao discurso sindical, que, segundo ela, sugerem a existência de apenas um sexo como constituinte da classe trabalhadora. Cabe, no entanto, ampliar a análise da autora, conferindo sua expressão crítica não só ao discurso sindical, mas às organizações políticas da esquerda, às profissões, à família, à igreja, aos partidos. Essa relação ainda é muito contemporânea em nossa sociedade quando mantém diferenças e hierarquias entre mulheres e homens com base no chamado sistema patriarcal-racista e capitalista.

Isso significa que os processos históricos travados pela classe trabaIhadora - processos em que homens e mulheres almejam a transformação radical das relações de opressão, lutam pela liberdade e justiça - devem atentar para o enfrentamento e o combate ao patriarcado enquanto modo de vida que subalterniza as mulheres. Em outros termos, exige postura crítica quanto ao modo de vida que supervaloriza o papel do homem, dando poder a este sobre a própria vida das mulheres.

No caso particular da ditadura civil-militar, constituíram-se governos comandados por militares, quer dizer, feito para homens e comandados por homens. Nessa cultura autoritária e machista, quando as mulheres 
apareciam era como "objetos decorativos" em jornais, em inaugurações, mulheres e crianças que apoiavam a figura do patriarca. A sociedade civil à época tinha a concepção da mulher como figura ligada ao espaço doméstico, ao cuidado da casa, o que era muito comum. Estranha que ainda hoje se mantenha esse papel subordinado da mulher na política, mesmo em setores de pensamento à esquerda.

Nessa concepção que liga a mulher ao papel restrito à maternidade, encontramos o reforço da divisão sexual do trabalho, que penaliza as mulheres, responsabilizando-as pelo cuidado com os demais membros da estrutura familiar. Um cuidado que oculta o trabalho doméstico não remunerado e a reprodução social das desigualdades sociais imposta ao feminino.

Neste sentido, cabe recorrer às contribuições de Safiotti (2004), uma referência singular nos estudos que articulam feminismo, patriarcado e capitalismo. Segundo relato de Heleieth Saffioti no documentário Um X na questão, o Estado brasileiro e seus aparelhos de repressão viam as muIheres como tolas, bobas, incapazes de se incorporar à luta política naquele momento. Esse preconceito acabou por fazer com que elas pudessem transitar mais facilmente na cena política, atuando na transmissão de informações e absorvendo tarefas que os homens tinham mais dificuldade de realizar. Isso, no entanto, não significou que tenham ficado dentro dos "aparelhos", varrendo o chão ou fazendo café.

Elas estiveram em todas as frentes da resistência. Foram muitas as que optaram pela luta armada e, sem que se julgue aqui o mérito de suas escolhas ideológicas e políticas, empunharam armas e foram literalmente à luta. Outras muitas, ainda que sem armas, colocaram em risco suas vidas e as de seus filhos e maridos ao estabelecerem também as suas estratégias de luta. Outras tantas já não estão entre nós para contar suas histórias. Ousadas demais, foram silenciadas (MERLINO; OJEDA, 2010).

A autora considera o patriarcado um regime atual, que orienta as relações homem/mulher, por ser uma expressão de poder político que dá direitos sexuais aos homens sobre as mulheres. Isso se configura como um tipo de hierarquia que contamina todos os espaços da sociedade, possuindo uma base material que representa uma estrutura de poder baseada na ideologia e na violência. De fato, o processo de exploração-dominação legitima a hierarquização masculina na sociedade ao estabelecer a liberdade para os homens e a submissão às mulheres.

\section{Considerações finais}

A ditadura civil-militar de 1964-1985 ainda não foi amplamente discutida e analisada, tanto em relação ao momento histórico em si quanto em suas consequências na contemporaneidade, mas este artigo ousa tocar 
em aspecto até recentemente silenciado, que ficava na memória subterrânea de algumas protagonistas daquele doloroso processo histórico. Assim, tratase, aqui, da análise da experiência de mulheres que resistiram à ditadura, que lutaram e sofreram a dor indizível das várias violências exercidas pelos agentes públicos do Estado.

Nesse sentido, permanece como desafio explicitar as resistências vivenciadas pelas mulheres em um período no qual a política de repressão é praticada e levada ao extremo pelo poder do Estado - político, policial e militar, quando the foi outorgado direito sobre o corpo, a mente, a vida e a morte das pessoas e, em particular das mulheres, na forma de estupros e outras violências extrema, autoritarismo e violação de seus direitos.

Durante a ditadura, as mulheres que militaram nas lutas de resistência não somente foram vítimas de uma violência estatal extrema; foram também vítimas do silenciamento de sua condição de mulher no ambiente de militância política. Engajadas na luta política de resistência à ditadura, as militantes de esquerda lutaram e resistiram aos vários preconceitos no âmbito público e privado. Uma reviravolta ocorre somente nos anos 1970, em especial, a partir da organização das que estavam no exílio e foram influenciadas pelo feminismo europeu. Elas procuraram construir proposta ideológica que revertesse a desigualdade e opressão masculina, a própria eliminação das hierarquias sexuais.

Com a redemocratização dos anos 1980, o feminismo no Brasil avança com a organização de inúmeros grupos e coletivos em todas as regiões, articulando pautas sociais de caráter mais amplo, porém sem descuidar de suas bandeiras particulares e voltadas à emancipação, à igualdade e à superação da violência. Com esses parâmetros segue a luta das mulheres cotidianamente na perspectiva de um futuro em novas condições. 


\section{Referências}

ALVAREZ, S. Feminismos latino-americanos. Revistas de Estudos Feministas, Rio de Janeiro, n. 2, 1998.

ALVES, M. E. R.; VIANA, R. (Org.). Política para as mulheres em Fortaleza: desafios para as desigualdades. São Paulo: Fundação Friedrich Ebert, 2008. ÁVILA, M. B. Feminismos, pesquisa e produção do conhecimento em Serviço Social. In: TEIXEIRA, M.; ALV ES, M. E. R. (Org.). Feminismo, gênero e sexualidade: desafios para o Serviço Social. Brasília: Editorial Abaré, 2015.

CAMURÇA, S. Nós Mulheres e nossa experiência comum. Cadernos de Crítica Feminista, ano I, dez. 2007.

BELTRÁN, E. et al. Feminismos: debates teóricos contemporâneos. Madrid: Alianza Editorial, 2

CARVALHO, L. M. Mulheres que foram à luta armada. São Paulo: Globo, 1992.

CISNE, M. Gênero, divisão sexual do trabalho e serviço social. São Paulo: Editora Outras Expressões, 2012.

COLLING, A. M. A resistência da mulher à ditadura militar no Brasil. Rio de Janeiro: Rosa dos Ventos, 1997.

DELPHY, C. Teorias do patriarcado. In: HIRATA, H. et al. (Org.). Dicionário crítico do feminismo. São Paulo: Editora Unesp, 2000.

FARIA, N.; NOBRE, M. N. (Org.). O trabalho das mulheres: tendências contraditórias. São Paulo: SOF, 2014.

GOLDENBERG, M. Mulheres e militantes. Revista Estudos Feministas, Florianópolis, v. 5, n. 2, 1997.

GURGEL, T. O feminismo como sujeito coletivo total: a mediação da diversidade. Cadernos da Crítica Feminista, ano V, n. 4, dez. 2011.

IPEA. Instituto de Pesquisa Economica Aplicada (Ipea). [2020]. Disponível em: www.ipea.gov.br. Acesso em: 10 out. 2013.

KERGOAT, D. Dinâmica da consubstancialidade das relações sociais. Revista Novos Estudos, n. 86, mar. 2010.

LEITE, R. de S. C. Brasil Mulher e Nós Mulheres: origens da imprensa feminista brasileira. Revista de Estudos Feministas, Florianópolis, v. 11, n. 1, jan./ jun. 2003.

MERLINO, T.; OJEDA, I. (Org.). Direito à memória e à verdade: luta, substantivo feminino. São Paulo: Caros Amigos, 2010.

PATEMAN, C. O contrato sexual. Rio de Janeiro: Paz e Terra, 1993. 


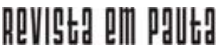

\} FEMINISMO E MULHERES - ALVES, M. E. R. \}

DOI: $10.12957 /$ rep.2021.56080

PINTO, C. R. Uma história do feminismo no Brasil. São Paulo: Editora Fundação Perseu Abramo, 2003.

SAFFIOTI, H. I. B. Rearticulando gênero e classe social. In: COSTA, A. O.; BRUSCHINI, C. (Org.). Uma questão de gênero. São Paulo: Fundação Carlos Chagas, 1992.

SAFFIOTI, H. I. B. Gênero, patriarcado e violência. São Paulo: Fundação Perseu Abramo, 2004.

SARTI, C. A. Feminismo no Brasil: uma trajetória particular. Cadernos de Pesquisa, São Paulo, v. 64, fev. 1998.

SOARES, $\mathrm{V}$. O feminismo e o machismo na percepção das mulheres brasileiras. In: VENTURINI, G.; RECAMAN, M.; OLIVEIRA, S. (Org.). A mulher brasileira nos espaços público e privado. São Paulo: Fundação Perseu Abramo, 2004.

SOUZA-LOBO, E. de. A classe operária tem dois sexos. São Paulo: Editora Brasiliense, 1991.

VENTURA, Z. O ano que não terminou. São Paulo: Editora Planeta, 1988.

DOI: $10.12957 /$ rep.2021.56080

Recebido em 09 de março de 2020.

Aprovado para publicação em 15 de maio de 2020.

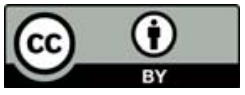

A Revista Em Pauta: Teoria Social e Realidade Contemporânea está licenciada com uma Licença Creative Commons Atribuição 4.0 Internacional. 